\title{
A COMUNICAÇÃO PARA TRANSMITIR A CULTURA E OS VALORES ORGANIZACIONAIS: O CASO DA REVISTA RECRUTINHA
}

\author{
Camila Cassins Jordão ${ }^{1}$ \\ Elza Aparecida de Oliveira Filha ${ }^{2}$
}

\begin{abstract}
Resumo: Este artigo analisa, sob a perspectiva da comunicação organizacional, quatro edições da revista em quadrinhos Recrutinha, produzida pelo Centro de Comunicação Social do Exército para crianças do primeiro ciclo do ensino fundamental. Como a revista apresenta o Exército Brasileiro sob um caráter didático, é possível perceber em seu conteúdo a transmissão dos valores e da cultura desta instituição, além de características próprias de sua comunicação.
\end{abstract}

Palavras-chave: Comunicação, cultura organizacional, história em quadrinhos, revista, Exército Brasileiro.

\begin{abstract}
This paper analyzes, from the perspective of organizational communication, four issues of the magazine Recrutinha, produced by the Communication Center of the Army for children of the first cycle of elementary school. As the magazine presents the Brazilian Army under a didactic approach, we can see in its content the transmission of values and culture of this institution, as well as characteristics of its own way of communication.
\end{abstract}

Keywords: Communication, organizational culture, comics, magazine, Brazilian army.

\section{Introdução}

Este artigo tem como objetivo analisar a revista em quadrinhos Recrutinha sob a perspectiva da Análise do Discurso de linha francesa (AD). A revista é produzida pelo Exército Brasileiro e tem como público-alvo crianças do primeiro ciclo do ensino fundamental. A publicação, conforme será abordado adiante, reflete uma série de peculiaridades da comunicação da instituição que perduram desde o Regime Militar (19641985), entre elas a exaltação do que é “de dentro", dada por meio da valorização da participação da instituição no desenvolvimento nacional e do culto a determinados heróis.

A escolha da revista Recrutinha se deve à falta de estudos sobre as formas alternativas de publicações organizacionais. Para a análise, foram selecionadas quatro edições, equivalentes ao período de um ano (2010-2011), material ao qual as autoras tiveram acesso. Como fundamentação teórica, foram usadas, sobretudo, obras de Margarida Kunsch (2009a, 2009b e 2009c).

\footnotetext{
${ }^{1}$ Jornalista (Universidade Positivo), aluna de Comunicação Institucional na Universidade Tecnológica Federal do Paraná (UTFPR).

2 Doutora em Comunicação pela Unisinos, professora do Departamento Acadêmico de Linguagem e Comunicação da UTFPR.
} 


\section{A Comunicação Social do Exército (CCOMSEX)}

O Centro de Comunicação Social do Exército (CCOMSEX), sediado em Brasília, é responsável por planejar, desenvolver e coordenar as atividades do Sistema de Comunicação Social do Exército (SISCOMSEX). Tem como objetivos “obter o ajustamento e a interação entre o Exército e seus públicos, informar e responder aos questionamentos desses públicos e influir nas emoções, nas atitudes e nas opiniões dos grupos sociais” (VERDE-OLIVA, 2011, p. 7).

Por se tratar de uma organização de caráter nacional, o público do Exército acaba se dividindo entre militares da ativa, reservistas e funcionários civis (público interno) e o restante da população brasileira (público externo). As crianças se enquadram como público externo, mesmo quando dependentes de militares. Sua inclusão na comunicação social se deve à necessidade de informar e influenciar, ao mesmo tempo em que se preservam a história e a imagem do Exército. Conseguindo uma comunicação eficiente com as crianças, é possível garantir uma boa imagem e posterior integração e sensibilização, cumprindo, a longo prazo, outros objetivos da comunicação social.

\section{Conceitos de Cultura, Identidade e Imagem Aplicados ao Exército Brasileiro}

A cultura e a identidade da organização se constroem e se afirmam perante o grupo através da comunicação. Apesar de não poder controlar como sua imagem é percebida, uma organização sempre irá buscar vincular-se a valores por ela julgados positivos, de modo a atrair estes públicos: "Há um esforço por parte das organizações em criar uma impressão pública que atraia o público de seu interesse, ou seja, há uma intencionalidade implícita na imagem organizacional, a qual determina seu gerenciamento" (ALMEIDA, in KUNSCH, 2009b, p. 228). A principal característica desta retórica é a autorreferencialidade, centrada nas intenções e estratégias de seu produtor (IASBECK, in KUNSCH, 2009b, p. 22).

Não se deve, porém, acreditar que essa imagem é constituída apenas através do discurso. Segundo Torres Junior, a mensagem organizacional está presente "em símbolos, falas, ações na cultura, nos objetos, na empresa como um todo, e não apenas no desempenho de um orador" (TORRES JUNIOR, in KUNSCH, 2009b, p. 72). É o que também defende Restrepo (apud KUNSCH 2009a, p. 78): “A comunicação em e das organizações deve ser entendida de uma maneira integral, reconhecida como presente em todas as ações de uma 
empresa ou entidade, configurando de maneira permanente a construção de sua cultura e identidade, marcando um estilo próprio e, por fim, suas formas de projetar-se ao exterior”.

Apesar de haver diversas concepções de cultura, neste artigo será usada a perspectiva de Driskill e Brenton. De acordo com os autores, a cultura é constituída de "valores (elemento-mestre); elementos simbólicos (símbolos, história, linguagem e metáforas); modelo (heróis); elementos interativos (ritos e rituais, estilo, comunicação organizacional); e elementos contextuais (histórias, lugares)" (DRISKILL e BRENTON, 2005 apud MARCHIORI, in KUNSCH, 2009b, p. 304).

Esses elementos constitutivos da cultura refletem na identidade da organização. Luiz Carlos Assis Iasbeck defende que identidade "está associada a tudo o que é inerente ao seu modo de ser, sua conformação, sua razão de existir” (IASBECK, in KUNSCH, 2009b, p. 10) e é formada "pelo seu lugar social, sua missão, pelo modo de atuação, pelas respostas que fornece ao meio ambiente e pelos insumos que dele recebe para manter-se integrada, atuante e persistente" (idem, ibidem).

Assim, não apenas no discurso verbal dos personagens, mas também na linguagem não verbal, a revista Recrutinha tenta atrair o público infantil e legitimar o Exército Brasileiro, dentro de um padrão de comunicação que é desenvolvido pela organização desde o Regime Militar.

Foi preciso, inicialmente, delimitar estes conceitos, para que se possa, a seguir, aplicálos à análise do Exército Brasileiro. Perceber os traços de sua cultura é essencial neste trabalho, pois somente assim será possível encontrar sua ressonância na revista Recrutinha.

O Exército Brasileiro é a Força Armada responsável pela defesa do país em âmbito terrestre. $\mathrm{O}$ crescimento do Brasil ocorreu vinculado às Forças Armadas, sobretudo ao Exército, que garantiu a permanência das fronteiras e a coesão nacional (SODRÉ, 1979). Castro (2002) explica que, com Proclamação da República, foram gerados conflitos internos dentro do Exército Brasileiro, por questões políticas, que perduraram até o Estado Novo (1937-1945). Para manter a integridade institucional da organização, foi necessário "inventar" a instituição:

Mais do que a 'reorganização' de uma instituição fragmentada após décadas de clivagens organizacionais e ideológicas, o que ocorreu foi a invenção do Exército, como uma instituição nacional, herdeira de uma tradição específica e com um papel a desempenhar na construção da nação brasileira. Vencidas as resistências internas 
e externas e os projetos alternativos, chegou-se a um arranjo organizacional e simbólico (CASTRO, 2002, p. 11-12).

Deste modo, foram tomadas decisões como, por exemplo, a criação de um patrono para o Exército, o Duque de Caxias. "A palavra francesa patron tem o duplo sentido de 'patrono' (protetor) e 'padrão' (modelo). O termo 'patrono' não existia, até então, na tradição militar brasileira" (idem, ibidem, p. 18). Também foi instaurado o Dia do Soldado por ocasião do aniversário de Caxias, e desenvolveram-se as comemorações desta data.

Outra comemoração que surge posteriormente é do Dia do Exército no dia da Batalha de Guararapes (19/04/1648): “Com isso, além de 'modeladores da nacionalidade', os bravos de Guararapes teriam sido também inovadores na arte militar, dando nascimento à doutrina militar brasileira" (idem, ibidem, p. 74). Pode-se dizer que, a partir desta "invenção" estabeleceram-se a cultura e, consequentemente, valores do Exército Brasileiro que perduram até hoje.

\section{Histórias em Quadrinhos}

O uso da imagem para contar histórias é feito desde as origens da humanidade, retratando-se ensinamentos, mitologias, ideologias e morais através de pinturas em paredes de cavernas, por exemplo. De acordo com Andrade Júnior (2005, p. 74), as "histórias são narrativas que organizam as crenças sobre a organização e seu sistema de valores, funcionando como um guia". Além disso, segundo Barbosa, o uso das histórias é uma forma de comunicação organizacional, pois cria "relacionamentos de valor entre os públicos estratégicos, garantindo o processo de negociação e de fortalecimento da reputação organizacional" (2010, p. 46).

A apreensão das histórias se torna melhor para as crianças através dos quadrinhos, pois antes de aprender a palavra escrita, elas aprendem a interpretar desenhos e imagens. Conforme ressalta Santos, "a união de texto e desenho consegue tornar mais claros, para a criança, conceitos que continuariam abstratos se confinados unicamente à palavra" (2003, p. 4). Assim, usar esta forma de sequência visual se justifica no caso da revista Recrutinha devido ao seu público-alvo. Conforme explica Villardi:

Sabe-se que toda a impressão, isto é, a reação íntima do indivíduo (no caso, as crianças) advinda de determinada situação ou experiência, é formada por uma série 
de imagens. A primeira etapa do processo imaginativo é chamada seleção que se refere à separação que a criança faz das imagens mais interessantes depois de compará-las entre si, conservando-as na memória. Estes elementos selecionados sofrem transformações se caracterizando assim em um processo dinâmico, pois estas impressões sofrem influências internas (sentimentos e desejos da criança). [...] A última etapa deste processo é a associação, a qual é responsável pela união dos elementos selecionados primeiramente já modificados, isto é, já influenciados internamente combinando-os e ajustando-os em um todo imaginário complexo (VILLARDI, 2007, p. 24).

O que se deseja ao utilizar a sequência visual dos quadrinhos para contar a história é transmitir a experiência, no caso as histórias e valores do Exército Brasileiro, às crianças.

\section{Recrutinha}

A revista Recrutinha conta com quatro edições anuais, para distribuição nas semanas do Exército e do Soldado e, ainda, em outras datas cívicas e em operações militares de vulto. Em seu enredo, os soldados Recrutinha e Olivinha ensinam grupos de crianças sobre diversos aspectos do Exército Brasileiro. No caso das edições aqui analisadas, são retratadas a história do General Sampaio e da Academia Militar das Agulhas Negras, ambas por ocasião de seus 200 anos, situações interessantes ao dia da Bandeira (história da bandeira, significado, quando deve ser hasteada, onde deve ser posicionada, a tradição de queimar as bandeiras consideradas velhas) e, por fim, o dia do Soldado, que também discute um pouco sobre o patrono do Exército, Luís Alves de Lima e Silva, o Duque de Caxias - uma vez que o dia do Soldado foi instituído em sua homenagem.

Deve-se observar que as ilustrações normalmente são feitas por Luiz Fernando Vieira (pela ausência do posto, deduz-se que é um civil), porém, na edição do dia da Bandeira, foram feitas pelo Coronel Ajax, Sargento Salvino e Soldado Macedo, ficando visível não apenas a diferença estética, mas também a mudança nos personagens (além do soldado Olivinha não aparecer, muda-se o grupo de estudantes e a faixa etária - na edição do Dia da Bandeira o grupo é menor e os estudantes são mais velhos). O ambiente, usualmente a escola e que depois muda para um quartel, de acordo com a edição, também se altera nesta edição, em que desde o princípio os estudantes já estão caminhando com o soldado Recrutinha.

Além das histórias, a revista conta com passatempos como figuras para colorir, cruzadinhas, exercícios de associação (entre figuras, por exemplo) e jogo dos erros, que reforçam o conteúdo visto. Por fim, as edições contam com canções relativas àquela edição 
(quando há) ou um breve texto sobre o assunto da edição e propaganda da Associação de Poupança e Empréstimo (POUPEX), que financia a elaboração das revistas e que pertence ao Exército Brasileiro.

A revista conta, ainda, com o mural do Recrutinha, em que são enviadas fotos de crianças com uma pequena frase (nome, idade, onde mora e, às vezes, algum recado para o Recrutinha). É interessante ressaltar que, neste mural, muitas das fotos publicadas são de crianças fardadas ou usando roupas alusivas ao Exército Brasileiro, como coturno e camiseta camuflada.

\section{Exemplos: Culto aos heróis militares e exaltação da importância do Exército}

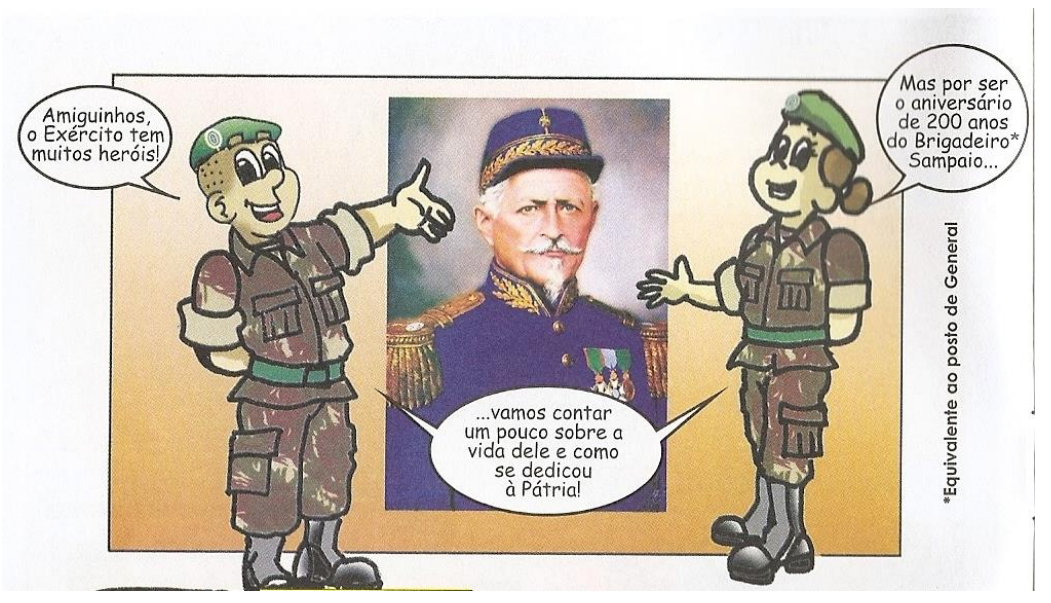

Figura 1: Conforme se observa na frase do Recrutinha, "o Exército Brasileiro tem muitos heróis!" (RECRUTINHA, maio/2010, p. 4, grifos da autora). 


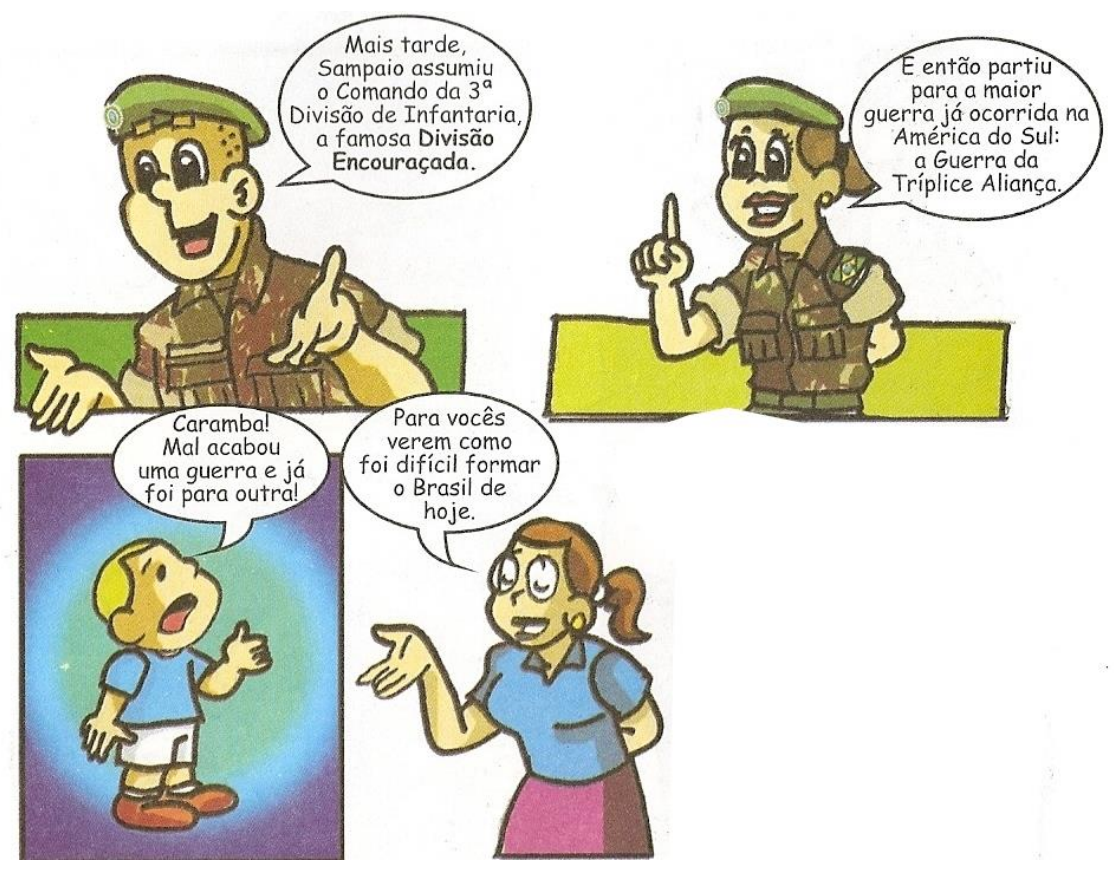

Figura 2: Conforme se observa na frase da professora, "Para vocês verem como foi difícil formar o Brasil de hoje", associa-se o Exército e as guerras à formação do Brasil (idem, ibidem, p. 9).

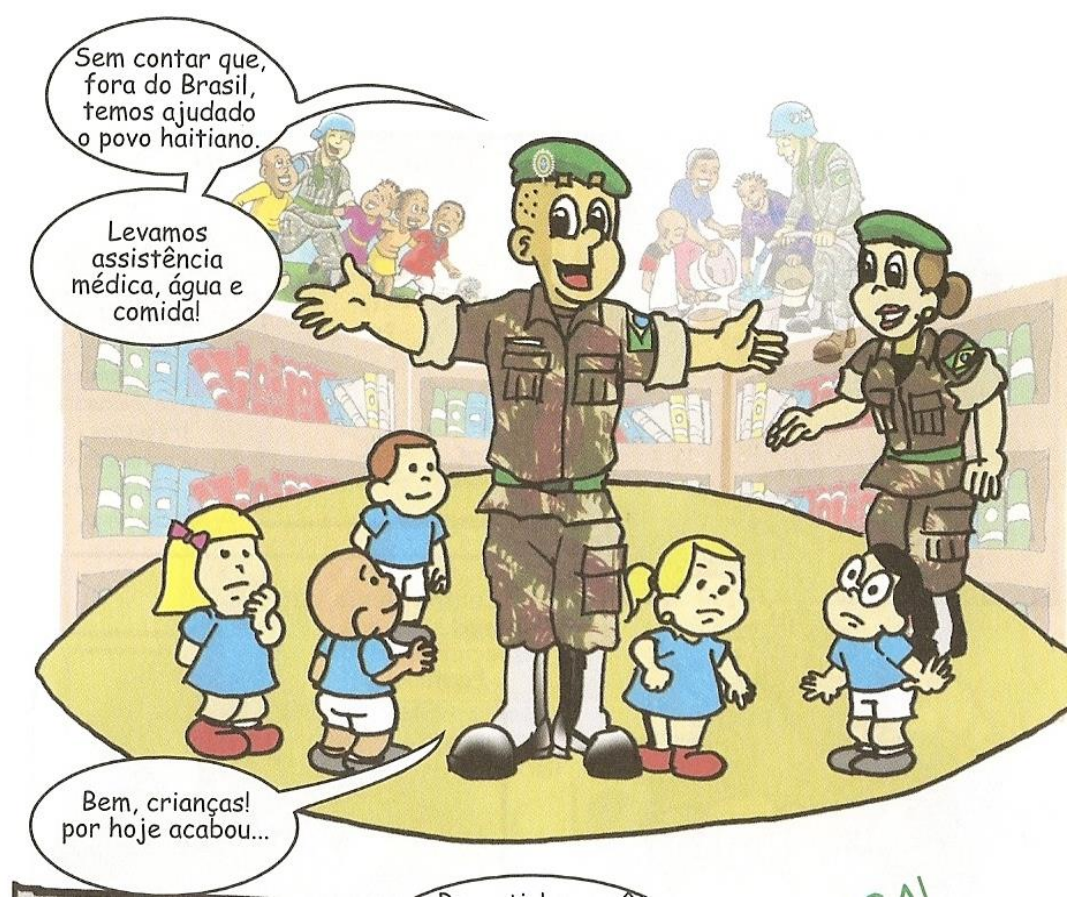

Figura 3: Ressalta-se a importância da atuação do Exército Brasileiro no Haiti (RECRUTINHA, 25/08/2010,

p. 16). 


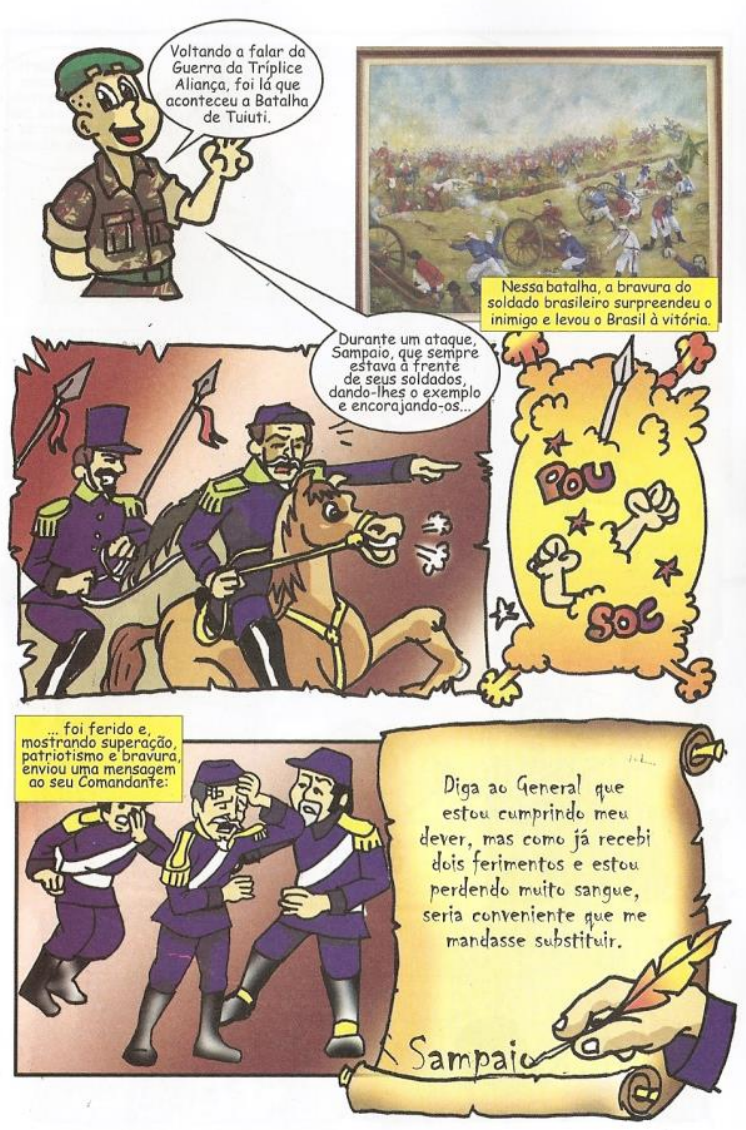

10
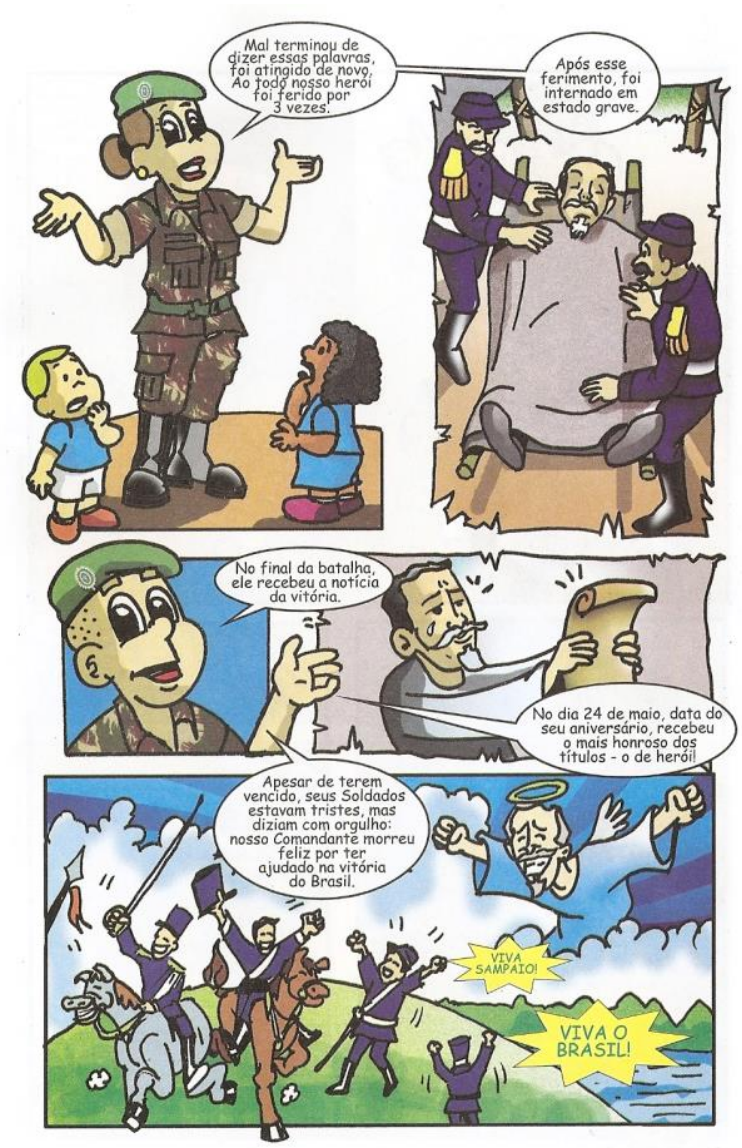

11

Figura 4: Características da profissão militar e do Exército Brasileiro são reforçadas (idem, ibidem, p. 10-11). 

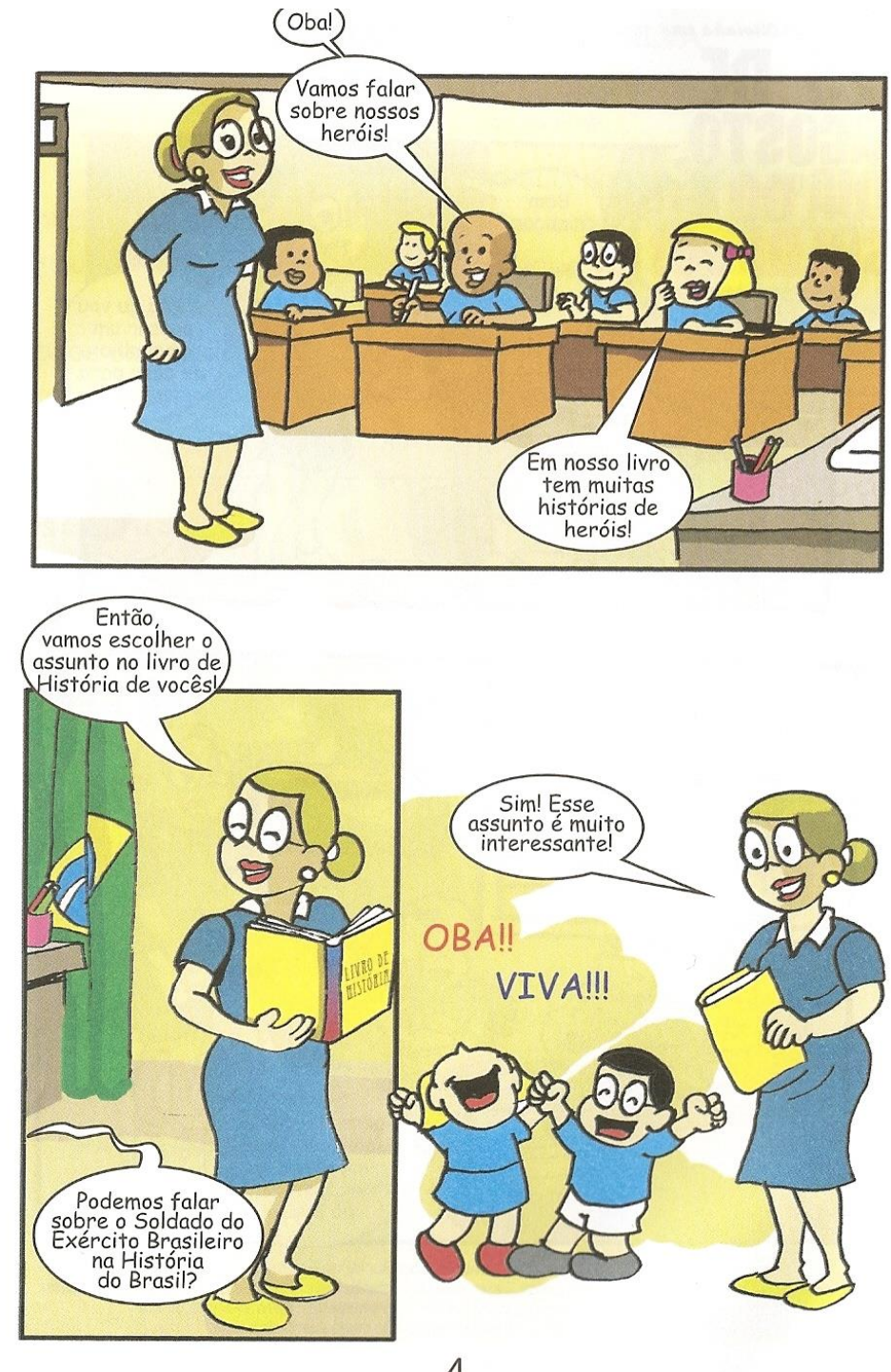

4

Figura 5: Novamente, a edição introduz as histórias de heróis militares. Desta vez, os alunos pedem para discutir sobre o Soldado do Exército Brasileiro, o que é visto positivamente pela professora: "Sim! Esse assunto é muito interessante!". A permissão para tratar do assunto gera ávida comemoração dos alunos, o que pode ser percebido pelas expressões faciais, braços erguidos, as exclamações e o uso de caixa alta. (RECRUTINHA, 25/08/2010, p. 4). 


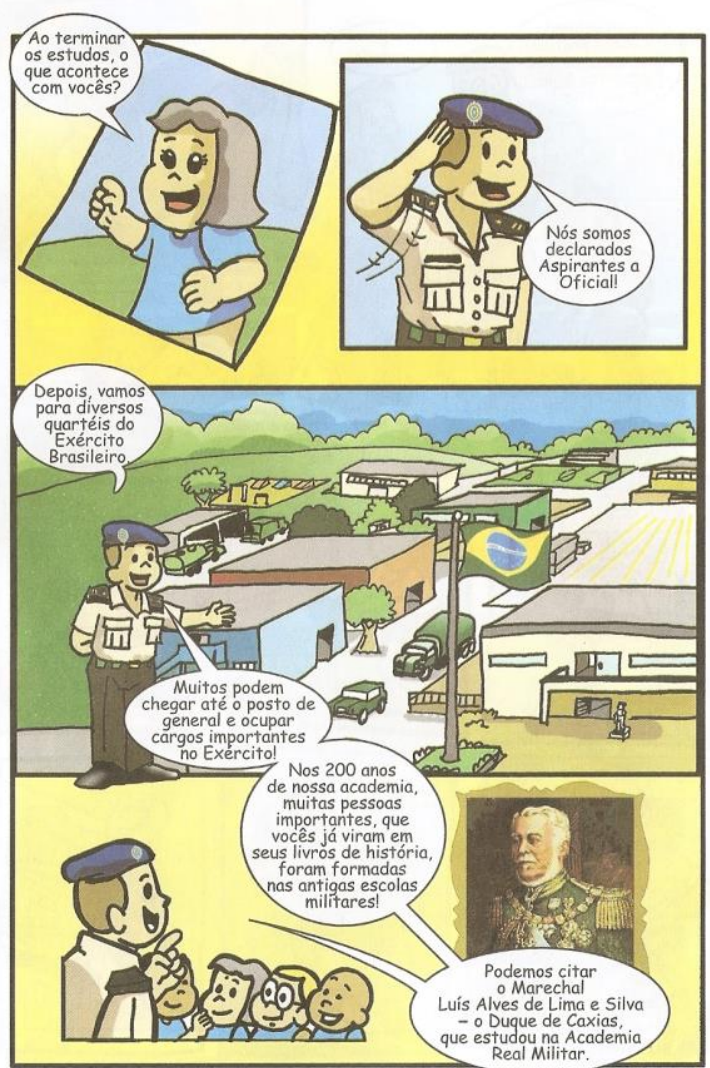

16
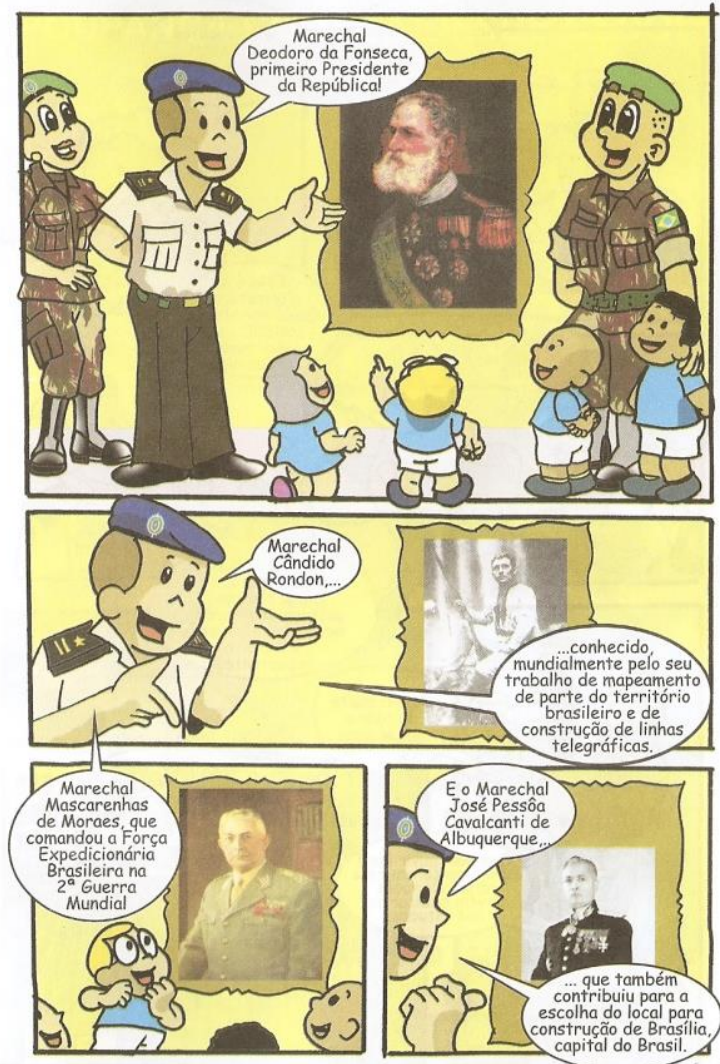

Figura 7: Culto aos heróis e demonstração da sua importância para a história do Brasil (RECRUTINHA, abril/2011, p. 16-17). 


\section{Outras formas de conteúdo}

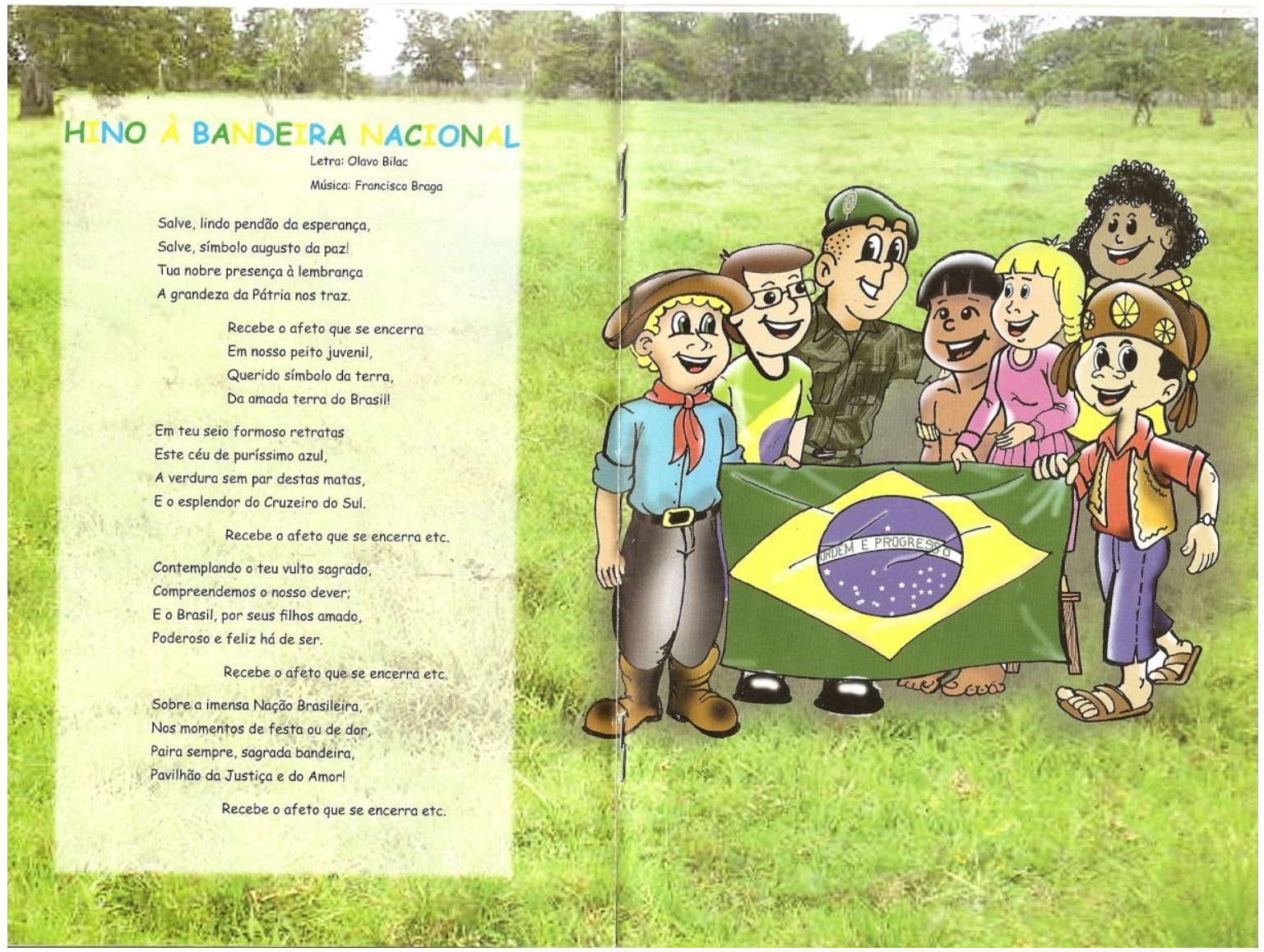

Figura 8: Hino da Bandeira Nacional na Edição Especial do Dia da Bandeira. Na ilustração, representação de crianças de diversas origens segurando a bandeira, junto ao personagem Recrutinha. Ideia de união nacional (RECRUTINHA, 19/11/2011, p. 8-9). 


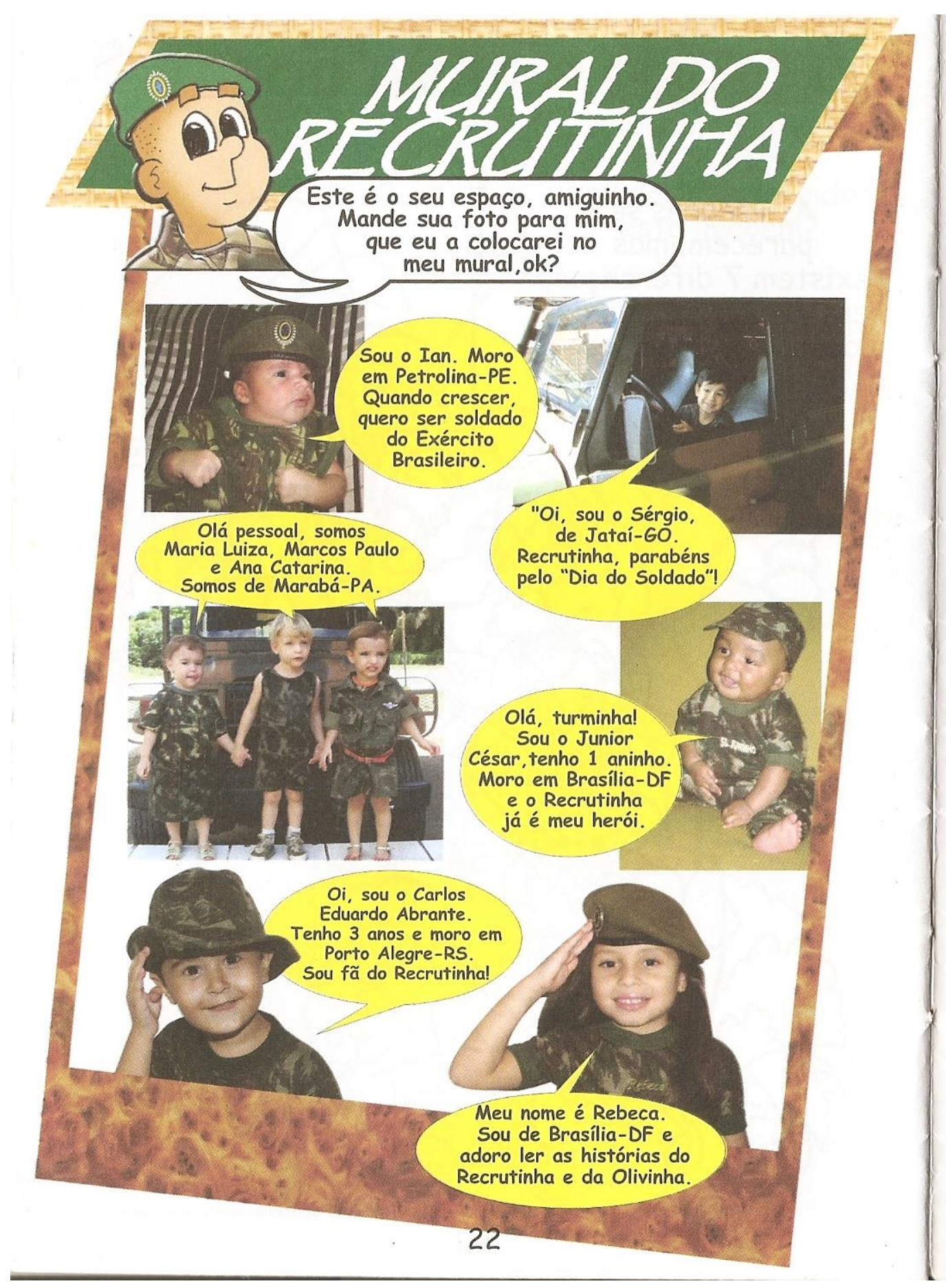

Figura 9: Mural do Recrutinha, com fotografias dos leitores. Nesta edição, em especial, nota-se que todas as crianças usam roupas alusivas ao Exército Brasileiro. Também é possível observar na fala de uma das crianças “... o Recrutinha já é meu herói” (RECRUTINHA, 25/08/2010, p. 22). 


\title{
Considerações Finais
}

De acordo com o site oficial da instituição, são valores por ela cultuados:

\begin{abstract}
Patriotismo - amar à Pátria - História, Símbolos, Tradições e Nação - sublimando a determinação de defender seus interesses vitais com o sacrifício da própria vida. Dever - cumprir a legislação e a regulamentação, a que estiver submetido, com autoridade, determinação, dignidade e dedicação além do dever, assumindo a responsabilidade pelas decisões que tomar.

Lealdade - cultuar a verdade, sinceridade e sadia camaradagem, mantendo-se fiel aos compromissos assumidos.

Probidade - pautar a vida, como soldado e cidadão, pela honradez, honestidade e pelo senso de justiça.

Coragem - ter a capacidade de decidir e a iniciativa de implementar a decisão, mesmo com o risco de vida ou de interesses pessoais, no intuito de cumprir o dever, assumindo a responsabilidade por sua atitude. (EXÉRCITO BRASILEIRO, 2013).
\end{abstract}

Conforme foi visto nas imagens anteriores, a característica predominante no discurso da revista Recrutinha é o patriotismo. As demais, porém, são retratadas ao falar sobre os heróis, em especial na edição sobre o General Sampaio. Outras características que aparecem na revista dizem respeito à profissão militar. Ao retratar a história do general Sampaio, procura-se integrar os valores organizacionais às características da profissão, como risco à vida, dedicação exclusiva e disponibilidade permanente, formando em Sampaio um verdadeiro "ideal organizacional".

Esta ligação entre o herói e os valores da organização é explicada por Andrade Júnior, segundo o qual, "Os heróis organizacionais são indivíduos que desempenham papéis organizacionais que personificam o sistema de valores e até mesmo definem o conceito de sucesso da organização" (ANDRADE JÚNIOR, 2005, p. 75).

O Centro de Comunicação Social do Exército Brasileiro (CCOMSEX) busca transmitir os objetivos da Comunicação Social do Exército, de informar e integrar, retratando os valores cultuados pela instituição e a história da organização. Para isso, na Revista Recrutinha são usados, sobretudo, os heróis, além de se ressaltar a importância da instituição na formação do país e na garantia da ordem, em um discurso essencialmente autorreferencial e legitimador.

Outra peculiaridade desta revista é a forma de transmitir a mensagem: através não apenas da história em quadrinhos, mas de todo o conteúdo, como no "Mural do Recrutinha". Observa-se, assim, a retoricidade da mensagem, abordado no primeiro item deste artigo, 
além do potencial da memória institucional para agregar o público, ao mesmo tempo em que é preservada a história da organização.

\section{REFERÊNCIAS BIBLIOGRÁFICAS}

ANDRADE JÚNIOR, Hermes de. Os limites e desafios do pensamento militar brasileiro em relação à questão ambiental. 2005, 333 f. Tese (Doutorado em Ciências na área de Saúde Pública) Fundação Oswaldo Cruz, Rio de Janeiro, 2005.

BARBOSA, Andréia Arruda. A Memória Institucional como possibilidade de Comunicação Organizacional: O caso Exército Brasileiro. 2010, 188 f. Dissertação (Mestrado em Comunicação Social) Universidade Católica do Rio Grande do Sul, Porto Alegre, 2010.

CASTRO, Celso. A invenção do Exército Brasileiro. Rio de Janeiro: Jorge Zahar, 2002.

EXÉRCITO BRASILEIRO. Características da profissão militar. Disponível em: http://www.exercito.gov.br/web/guest/caracteristicas-da-profissao-militar. Acesso em: 24/02/2013.

. Síntese dos Deveres, Valores e da Ética do Exército. Disponível em: http://www.exercito.gov.br/web/guest/missao-e-visao-de-futuro. Acesso em: 20/07/2013.

KUNSCH, Margarida M. Krohling (Org). Comunicação Organizacional: histórico, fundamentos e processos, v. 1. São Paulo: Saraiva, 2009a.

(Org). Comunicação Organizacional: linguagem, gestão e perspectivas, v. 2. São Paulo: Saraiva, 2009 b.

(Org). Relações Públicas - História, Teorias e Estratégias nas

Organizações Contemporâneas. São Paulo: Saraiva, 2009c.

RECRUTINHA. Distrito Federal, Exército Brasileiro, 24 de maio de 2010. , Distrito Federal, Exército Brasileiro, Agosto de 2010. , Distrito Federal, Exército Brasileiro, Abril de 2011. 
, Distrito Federal, Exército Brasileiro, 19 de Novembro de 2011.

SANTOS, Roberto Elísio dos. A história em quadrinhos na sala de aula. In: XXVI Congresso Brasileiro de Ciências da Comunicação. Belo Horizonte. Disponível em: http://www.intercom.org.br/papers/nacionais/2003/www/pdf/2003_NP11_santos_roberto.p df. Acesso em: 22 jul. 2013.

SODRÉ, Nelson Werneck. História Militar do Brasil. São Paulo: Civilização Brasileira, $3^{\text {a }}$ edição, 1979.

VERDE-OLIVA. Distrito Federal, Exército Brasileiro, nº 211 Abr/Mai/Jun 2011. Disponível em: http://pt.calameo.com/read/0012382065c1b3eb1a36c. Acesso em: 29 Out. 2013.

VILLARDI, Marina Lemos. O imaginário infantil no âmbito escolar. 2007, 66 f. Monografia (Conclusão do Curso de Pedagogia) Universidade Estadual Paulista, Bauru, 2007. 